\title{
REVALUATION OF THE PROXEMICS CODE IN MEDIATIZED COMMUNICATION
}

\author{
Katarzyna Drąg ${ }^{7}$
}

\begin{abstract}
Technological progress in the field of media and communication as well as the dynamics of development of modern communication tools pose a challenge for studying the issue of space in communication and proxemics theory. The mediatisation of almost all aspects of human life is based on increasingly better communication tools that transform time-space relations in communication. Natural forms of interpersonal communication are increasingly being replaced by mediatized communication. Electronic communicators are becoming a kind of laboratory that modifies contexts, channels and codes of communication acts, especially in the proxemics field. Therefore, the purpose of our analyses is to show some aspects of these changes from the perspective of three basic proxemics categories: interpersonal distance, territoriality and space arrangement. In this way, we want to achieve the triple goal of our analysis: cognitive, research and practical. The cognitive goal is an attempt to show changes in the proxemics code in mediatized communication. The research goal is to describe the functioning of this code in electronic communication practice. However, the practical goal of our analyses is to point out the important rules for using proxemics in improving the quality of personality and efficiency of communication.
\end{abstract}

Keywords: proxemics, mediatized interpersonal communication, non-verbal communication, mediatisation of interpersonal communication

Technological progress in the field of media and communication as well as the dynamics of development of modern communication tools are not only a challenge for communication participants in terms of their communication competences and the ability to use these new tools, but also are a challenge for communication researchers in the application of traditional theories and research tools to an adequate description new phenomena and contexts and solving related problems. This challenge also concerns the issue of space in communication and the theory of proxemics.

For over half a century, since the popularization of the concept of proxemics by Edward Hall [Hall, 1959; Hall 1966] and, among others, researchers such as Albert Mehrabian, Robert Sommer, Mark Knapp and Umberto Eco, and this issue had rooted in scientific considerations. Proxemics has become the centre of interdisciplinary reflection in research. Psychology, sociology, philosophy, semiology and cultural anthropology deal with the issue of the importance of space in the lives of individuals and societies. Proxemics has also permanently entered the research in the field of social communication 
and media sciences.

Our analyses are an attempt to show the phenomenon of proxemics code re-evaluation in mediatized communication. Contemporary media sphere is not only a space for changing media, but also a whole sphere of mediatized social and interpersonal communication. The mediatisation of almost all aspects of human life is based on increasingly better communication tools that transform time-space relations in communication. The purpose of our article is to show some changes in spatial relations in communication implemented using electronic media. In our article, we assume basic knowledge about the phenomenon of mediatisation of communication and their theoretical description in theories of mediatisation, which is why we do not reach for the presentation of the theory of mediatisation due to the assumed methodological and content objectives of the article. These analyses are intended to show some aspects of mediatisation processes of interpersonal communication from the perspective of proxemics theory. For the operational purposes of this article, we understand the phenomenon of mediatisation as a multi-faceted phenomenon of using technical tools for the transmission of symbolic forms in social communication. This operational understanding of mediatisation allows for analytical probing of the causes, consequences and contexts of this phenomenon, which is a determinant of the development of media society and the formation of information civilization.

The phenomenon of mediatisation of life has its vital foundation not only in media communication, but also changes the quality of interpersonal communication, which is increasingly taking place in the media space [Lundby, Mouton, 2014]. Therefore, also for the purposes of better orientation and understanding of the analyses contained in the article, it is worth specifying the terminology used in it. The basic concept is media communication, which co-creates the modern media sphere. This term is used to describe the overall process of transmitting symbolic content using traditional and new media. The second concept is mediated communication. This term means processes of social communication supported by intermediary elements described in the theories of mediation and anthropological and psychological theories of communication. The main term used in this article is the concept of mediatized communication, where the concept of media is limited to technical tools as a means of media communication. This term defines all processes of interpersonal communication and social communication, which are supported by tools of communication technologies. The description of this phenomenon of mediatisation of communication is dealt with in communication theories, media communication theories and mass media communication theories. Our analyses place this kind of communication theory, showing some aspects of the phenomenon of proxemics changes in mediatized communication.

This phenomenon fully justifies the topicality of the research issues undertaken. The dynamics of mediation processes are also influenced by new social phenomena on a global scale. It is definitely a pandemic situation that began in 2019 in China. Forced quarantine, isolation, the need for remote work, in a way, forces the use of other proxemics rules and tools in social and interpersonal communication.

In these new social conditions, natural forms of interpersonal communication are being replaced more often and more widely by mediatized communication. Electronic communicators are becoming a kind of laboratory that modifies contexts, channels and codes of communication acts, especially in the proxemics field. Therefore, the purpose of our analyses is to show some aspects of these changes from the perspective of three basic proxemics categories: categories of interpersonal distance, territoriality and space arrangement.

A particularly interesting type of communication, intensified during the duration of restrictions related to the coronavirus pandemic, is communication via video communicators in professional and public situations. The widespread transition to such a form of contact at work in such areas as education, higher education, journalistic, political 
activities, etc. is an impulse to scientifically confront the known principles of proxemics with new communication realities. This is, of course, a very broad and diverse issue, so for the purposes of the article only selected aspects will be discussed.

Empirical research conducted with the use of the participatory observation method provided knowledge about the significant role of space in mediatized audio-visual communication. Studies have shown changes, tensions and proxemics dilemmas in video chats, often overlooked by those involved. Only the participant-observer's approach gave a greater chance to analyse the behaviour and proxemics elements that have a significant role in the process of communication. This knowledge, of a contributory nature, can be the basis for deriving several practical conclusions to be used by both the creators of communicators, communication moderators, as well as participants in video chats or video conferences:

The purpose of our article is to show, on the basis of theoretical analysis and empirical research by the method of participant observation, that proxemics diagrams that determine the way of life and communication of a person undergo re-evaluation in new situations of mediatisation of life and mediatized communication. The quality of these changes is so dynamic that it requires solid research analysis. The theory of proxemics, present in various analyses in the last decades of the development of this science, has developed many practical principles worth applying in the context of forced life situations of new proxemics situations in communication. That is why in our analyses we use the theory of proxemics to extract from it important rules that are worth applying in the changing practice of social communication. In this way, we want to achieve the triple goal and value of our analyses: cognitive, research and practical. The cognitive goal is an attempt to show changes in the proxemics code in mediatized communication. The research goal is to describe the functioning of this code in electronic communication practice. While the practical goal of our analyses is to point out the important rules for using proxemics in improving the quality of personality and efficiency of communication.

The achievement of these goals is possible due to the use of several research methods in the work. These are theoretical and empirical methods. The categories of the first methods include: a synthesizing method of analysing specific phenomena based on the theory of description of these phenomena. In our case, we refer to the theory of media communication, the theory of communication proxemics or the theory of mediatisation of communication. Another theoretical method used is the method of synthesis of subject knowledge, referring to specialist literature on the subject. The method of contributing analyses is not without significance for our analyses, which allows combining theoretical subject knowledge with empirical description of phenomena contained in the literature on the subject. The category of empirical methods used in the article includes the participatory observation method, thanks to which we obtain contributing knowledge about the phenomena we analyse. This article is an attempt to discover some aspects and proxemic contexts in mediatized communication. It has the character of probing the dimensions of this phenomenon based on both theoretical knowledge about the changing conditions of space in communication, as well as on the basis of empirical knowledge about the processes of these changes in interpersonal communication taking place in the world of new communication tools.

\section{Contextual communication potential of space}

\section{Space in the process of communication}

The communication context is a category necessary to study communication acts. The popularization of this aspect of communication was helped by the departure in linguistics from such research trends as structuralism or generative grammar, and the spread of pragmatism. "Communication, as a certain type of social activity, was analysed in the context of the social situation. It was recognized that the context for the 
analytical unit is not only directly related to other language expressions, but also non-linguistic circumstances accompanying the given expression" [Bielecka-Prus, 2012 p. 20].

Contemporary analyses of the communication process are based on the classic model of the communication act encapsulated in the categories of context, code, and channel. There are two basic levels of context analysis: linguistic (including words, sentences or whole fragments of statements that precede and follow a given statement), social (referring to the external situation in relation to the statement). Such a general division has been repeatedly detailed by researchers. In one of the suggestions, apart from the linguistic context, the interpersonal context (social roles, place of conversation, atmosphere of relations, etc.), the task context related to communication as an activity; cultural context (community of experiences and cultural behaviour scripts typical of a particular community) [Nęcki, 2000, p. 92-96].

A simple and functional typology of the context is the division into physical, social, psychological, historical and cultural context. The first applies to all physical conditions of the communication process: time, space, lighting, temperature, etc.; second draws attention to the category of social groups and their impact on the communication process; third refers to the psychological attitude of communication participants and their relationships; fourth to episodes from the past whose references affect communication; last to the cultural conditioning of communication, both to local culture and intercultural conditions [Lustig, Koester, 1996]. Typology of contexts is structuring, but this does not mean that the boundaries between individual contexts are in practice clearly outlined. On the contrary, the context of communication must be considered holistically, and its individual aspects not only affect the way of interpreting the speech, but also create tensions among themselves, as well as carry messages regardless of verbal communication.

Proxemics is associated with the contextualization of acts of communication. The space in which communication occurs is the context of this process. At the same time, land use has communication potential. Proxemics use context. Therefore, it is reasonable to place this issue in a broad context of contextual communication. Communication is carried out verbally and nonverbally, nonverbal elements of the communication process are largely contained in its context. Therefore, everything that relates to the analysis of space should be located and considered in its entirety the relationship between verbal and non-verbal communication.

Non-verbal communication, including proxemics messages, can perform a verbal communication function in relation to verbal communication, weakening verbal communication; it can deny verbal communication and can also be used to personalize verbal messages [Albert, 2019]. In addition, a non-verbal signal can occur independently of the verbal one and carry its own meaning. This applies fully to proxemics, which can be considered as a set of signals accompanying verbal communication or occurring independently. The following analyses and conclusions will concern the first situation, when space is the context of verbal communication and as such carries meaning.

\section{Proxemics categories in communication}

Generally, proxemics are defined as research directions related to the social perception and use of space treated as a cultural creation, assuming the basic assumption that the arrangement of individuals in space is associated with the expression of an emotional state and transmits specific content [Encyklopedia PWN]. Edward Hall defined proxemics as a study of the ways in which a person acquires knowledge by assessing behaviour patterns associated with varying degrees of intimacy between people, and studying human perception and use of space taking into account cultural conditioning [Hall, 1959, p. 41; Hall 1974, p. 2]. This broad issue includes various proxemics categories. These include, for example, such subsystems of spatial structures and corresponding proxemics behaviours as: technical development and organization of space; making 
spatial choices; spatial mobility; experiencing emotional states in relation to perceived space [Pióro, 1982, p. 113-130, Hareli, Hess, 2010, 128-140]. Proxemics analyses concern both the space between individuals and groups, as well as the relationship of people to objects, and the meanings of the elements of space themselves. Therefore, when trying to categorize proxemics, we can also use the division of this research field into the following: arrangement of elements in the physical environment, ecology of small groups, spatial relationships in the crowd, orientation of personal space, territoriality.

One of the most known and at the same time the most important proxemics categories are interpersonal distances proposed by Edward Hall. These include intimate, private, social and public distance. In the first distance (up to approx. $50 \mathrm{~cm}$ ) there are people who are connected by a strong emotional bond; in the second (from approx. 50 $\mathrm{cm}$ to approx. $120 \mathrm{~cm}$ ) there are usually people who know each other and have close relations with each other; in the third distance (from approx. $120 \mathrm{~cm}$ to approx. $360 \mathrm{~cm}$ ) there is contact in official situations, e.g. when dealing with business matters; the fourth distance (over $360 \mathrm{~cm}$ ) occurs during meetings such as public appearances, lectures, concerts. It should be remembered that such a categorization is only a model helpful in the analysis of proxemics relations, which is subject to modifications under the influence of cultural as well as individual and technological factors.

The concept of territoriality is also basic in analyses in the field of proxemics. Generally speaking, it is human behaviour related to the space of its functioning, attitude towards the immaterial environment and the message resulting from these relations. Territoriality manifests itself in social life in activities emphasizing control over a specific space or when a specific space belongs to an individual or a group.

Everyone is embedded in public spaces that are publicly available, but everyone also has a space they consider to be their own. It is a place where people from outside the immediate circle cannot enter without permission. The basic space is usually our house, a fenced property, which we treat as property and to which we guard access. A secondary space can be separated between this space and public space. These are places that are not someone's property, but can be associated with this person, they often use them. Public space is the one that can be used by all users and none of them has any grounds to claim exclusive use. Of course, temporarily individuals occupy fragments of public space and then use it, and social norms protect such places at a specified time against the intrusion of a stranger. If this occurs with the consent of the parties concerned. For example, when we sit on a bench in a public park space, we take the bench for ourselves. Social norm makes others willing to find a place elsewhere, or as the last resort to ask for permission to join you.

The third category important for further considerations is the arrangement of space, i.e. the appearance of the space, its arrangement, and the elements presented in it, which form the information carried on the basis of non-verbal messages. This is important when the space is intentionally arranged, prepared to carry the meaning specified by the sender, but equally important and interesting, when the space is found, it was not arranged specifically for the needs of a given act of communication. Both variants are worth considering in the context of interpersonal communication using new technologies. Space is perceived, used and constructed for communication purposes [Beaulieu, 2004, 794-805].

The categories of interpersonal distance, territoriality and space arrangement are important to the analysis of proxemics behaviour in the case of mediated communication using a video connection. Therefore, the following analyses will focus around these three categories.

\section{The role of proxemics in mediatized communication}

Following the basic, intuitive association, one could consider that proxemics, in 
principle, is associated with direct communication and plays an important role in such communication. Of course, at the time of extracting and defining proxemics as a means of information transmission, and during the first study of proxemics behaviours, there could be no question, for obvious reasons, of using these studies to analyse mediated and live interpersonal communication. Such a substitute for the most basic form of communication, which is face-to-face communication, came into widespread use several decades after undertaking the first structured research reflections on the meaning of proxemics. Of course, along with observation of direct communication, film and photography remained the field of research in this field throughout this time.

Modern technological solutions have given the opportunity to overcome the limitations of time and space. The media connect participants of the act of communication separated in geographical terms. The Internet has brought unprecedented transmission possibilities. Seeing and hearing live, offered by many messengers, has become an everyday communication. Mediated communication has become similar to a face-to-face meeting using efficient and widely available audio-visual communication.

The media modify the form of communication and change the communication rules prevailing until now [Sproull, Kiesler, 1986, p. 1492-1512; Baym, 1995, p. 138-163]. This state of affairs provokes scientific reflection. It also concerns proxemics. Interpersonal audio-visual communication has meant that theories describing computer-mediated communication as a social vacuum have become partly incompatible with reality. The belief that computer-mediated communication is devoid of relational features that can constitute social guidelines for communication participants must be challenged today [Hans, Hans, 2015, 47-52].

Contemporary communication is subject to the mediation process, in all its forms. The progressing mediation process, which involves the spread of the media and replacing the non-media with the media, as well as the merging of non-media and media activities, intensively affects the shape and course of acts of interpersonal communication. Changes to the existing patterns of interpersonal communication are based on the accommodation of mediated patterns, i.e. by gradually accustoming interlocutors to entering the media in everyday life.

Different types of communication are subject to mediation. Stanisław Michalczyk pointed out in this context: "a) mediatized interpersonal communication, b) interactive communication understood as communication between man and the" intelligent "hardware / software system, and c) mass communication which is the production and reception of standardized and generally addressable messages" [Michalczyk 2009, p. 21]. This list should be supplemented with a fourth category - mass communication, which is not a standardized product. Such communication is a consequence of universal, unlimited access to the possibility of unprofessional broadcasting on a mass scale. "The theory of mediation should answer the question: why and how the media and communication will continue to develop, and what consequences will this development have for human identity, culture, forms of cohabitation?" [Michalczyk 2009, p. 21].

In the context of such a general demand, digitally-mediated communication is also becoming a very interesting research field of proxemics analyses. The mediatisation of communication processes forces changes in understanding and re-evaluation of the proxemics code in its current shape. Categories such as basic for reflection on the importance of space in the communication process: interpersonal distance, territoriality or space arrangement gain new meanings require redefinition in contact with a new form of communication between individuals, which is live communication using audio-video technology.

\section{Video conversation proxemics - interpersonal distance, territoriality and space arrangement}


Video telephony nowadays provides a two-way transmission of both voice and image between many locations in real time. In the case of the form of communication, which is communication using video chat tools (to mention only the most popular: Skype, Viber, WhatsApp, Line, Google Duo), obviously, there is no direct contact for talking, but this does not mean that knowledge of the scale of interpersonal distances cannot be used here. There are many factors associated with leaving interlocutors in a certain distance: physical distance, voice level, and above all access or lack of it to details of the interlocutor's appearance, visual behaviour.

\section{Interpersonal distance}

During the video chat, we have a physical contact with the screen image of the interlocutor. Screen contact, however, is still subject to the principles of proxemics and provides ample scope for analysing the communication relationships of the interlocutors. "In proxemics research studies, the screen looks at the characters in three different aspects. The first is the proxemics of interpersonal relations, the second - the proxemics of the subject's reference to the camera, the third - the proxemics involving the relationship between the screen figure and what surrounds him, i.e. the world of various objects and phenomena. There is no need to see a fundamental contradiction between the non-mediatized and the mediatized view in the sense of polar opposition, although one should note the difference in certain behaviours and the significant difference that occurs in the conventionalisation degree of both. " [Hendrykowski, 2016, p. 41].

In the case of audio-visual contact, some factors resulting from the scale of interpersonal distance are suspended, while others still carry the meaning, although their known assignment to individual distances ceases to apply. It is worth asking the basic question about the existence and shape of boundaries between individual interpersonal distances in the case of communication using audio-visual communicators.

People communicating (screen character and physical interlocutor) although locally distant from each other over a large or a very large distance, location does not matter, but they observe themselves as if they were separated by a few tens of centimetres. During such communication, the interlocutors have access to information such as: detailed facial features, possible skin imperfections, makeup imperfections, clothes, and drowsiness in the eyes, i.e. to signals that are hidden in direct communication conditions, inaccessible to persons for whom contact is reserved within the social sphere. Although, obviously, it is not possible to touch a person in a physical sense during such communication, the distance separating the screen image and the biological form of the interlocutor is so small that in the conditions of direct conversation it would simply be unacceptable, it would indicate a very close intimacy between persons and mutual consent for potential uses of the haptic channel. This channel is launched outside the intimate and private distance only as part of the greeting or farewell scripts (e.g. handshake). During the video chat, on the one hand, we are not able to use touch, on the other, we remain seemingly in a distance that would allow this, and thirdly, we are accompanied by tactical substitute experiences: "Touch as breaking the distance turns out to be illusory. Reaching for a cell phone, remote control or laptop and establishing contact with others, we realistically touch the keyboard, and only in a virtual sense each other" [Hendrykowski, 2016, p. 62].

Talking in a social distance requires observing the rules of eye contact. Also in this respect, the mediation arising from the video chat changes the communication patterns, and most importantly, the meanings they convey. If we treat the audio-visual connection as a substitute for a face-to-face conversation, then we must be aware that it does not give the possibility of proper, i.e. one that we deal with in direct contact, the use of non-verbal communication in the field of eye contact. Eye contact in non-verbal communication carries meaning through its mere establishment, its length and frequency. Lack of eye contact may also be significant, "avoiding someone's eyes is as much as forcing 
him to stop talking and cut off the conversation" [Hall, 2003, p. 173].

Video chat gives the opportunity to see interlocutors, but it does not provide the possibility of making eye contact in the strict sense. It does not allow looking into the eyes, and thus blocks all meanings transmitted this way. In communication taking place at each of the distances, visual contact is present as an important signal differently implemented depending on the distance. Video chat allows people to look at each other, but not eye contact. The one for technical reasons is impossible. The caller would receive a signal that he was looking directly at him if his interlocutor was looking directly at the camera. However, of course, at the same time this interlocutor would not see the image of the interlocutor. Seeing a character and making eye contact are two different things. Classic distance scales refer in detail to this issue that cannot be realized in audio-visual mediated contact, despite its visual nature.

The above examples show how the rules arising from interpersonal distances are complicated when contacting in video chats. Individual spheres intertwine. It can be said that in the discussed communication situation not only the private sphere, but also the intimate sphere becomes a social sphere. Following this statement, it cannot be concluded that everyone should have access to these spheres, as it is the case in the social distance in direct contact. People outside the circle of loved ones gain access to such signals that would be unavailable to them in non-mediatized communication. Assumptions of social interpersonal distance penetrate intimate and private distance and change it.

\section{Territoriality}

Territoriality consisting in the separation and protection of those spaces that are considered the most private, reserved exclusively for the owner also requires commentary in the context of using video telephony. By establishing this form of communication, its participants agree to "let" the interlocutor in a virtual sense into the space they use when talking. Tools for audio-visual contact are now available for both desktop computers, laptops, tablets as well as smartphones, iPhones, i.e. mobile devices. Therefore, the space in which we can potentially establish a conversation can be almost limitless. It seems, however, that while mobile telephony allows and at the same time determines users to be always available, and so much video telephony from a sociological and cultural perspective does not impose constant availability to the same extent. We often ask about the possibility of visual connection, and we also arrange it more often. Although the tool is very widely available still, audio contact is basic, and the video option is widely available for people close to one another or for other people (e.g. for professional purposes) after mutual agreement [Li, 2001), 124-146].

For online meetings of larger groups using messengers, not everyone agrees to share the vision. An example would be the situation of remote education at the university. If a student participates in a meeting without sharing a vision while in his private space, there is no reason to force him to share it with other online participants. On the other hand, it requires prudence on the part of the teacher who, in principle, remaining in official relations with students can transmit many messages and shorten the interpersonal distance with students "inviting" them virtually to the private, personal centre of the world. The example of distance learning using audio-visual tools has become very up-to-date. Hasty disregard for the rules of territorialism, to which we are accustomed in direct contact, may affect the overall relationship in a given group in the future.

On the one hand, by letting someone enter your basic territory, you can communicate familiarity, on the other, by protecting this space, you can point to social distance and differentiate relationships. The sender should make such decisions consciously, also recognizing their possible consequences.

Audio-visual communication in supporting or public space can be another example of the complexity of proxemics relations in terms of territoriality. Since the management 
of this space and its sharing with other users is carried out according to social rules, it can be questioned by the virtual introduction of subsequent users of a given space by one of the real users. As in the example of the park bench used above by two strangers who agreed to share it, one might wonder whether it is appropriate for one of these people, after taking a seat, to partially share it with the next user with whom they have a video chat. Could such a situation and for what reasons be seen by the original stroller as inappropriate, uncomfortable? Is virtual sharing of public space conditioned differently than sharing it in non-indirect contact? The notion of territory fixed in proxemics must be redefined in the context of the progressing mediatisation of communication. Territoriality loses in this situation certain aspects (e.g. it is not possible to communicate that results from taking a specific place at the table, because the participants are not sitting together), but messages resulting from the instinct assigned to a man to recognize a given territory as their own, to protect it, to annex the territory, etc. they disappear from the communication space, they only change their shape.

\section{Arrangement of space}

A very important aspect of non-verbal communication that cannot be omitted in the description of the specificity of audio-visual contact is the arrangement of space, this part of space that is available to the interlocutor on the screen. Arranging a space means arranging its individual elements, adding or removing specific attributes in that space.

In a screen situation (using a communicator), what is important is what the interlocutor sees (the image surrounding the partner), as well as how he sees it (what is the perspective, angle of view, camera position, image texture, contrast, quality of the message, its fixed or moving nature). Arrangement of space, on the one hand, as a means of communication in video chat seems very limited (often visible only one frame), at the same time this means is very complex, because the final image reaching the interlocutor consists of many elements.

When considering the problem of space arrangement, one should mention the issue of intentionality in non-verbal communication. Non-verbal signs can be sent intentionally or intentionally, which is easier to assess from the sender's perspective, at the same time both characters sent intentionally or unintentionally by the recipient can be interpreted as intentional or unintentional. What on the recipient's side gives four possibilities of assessment [Knapp, 1979, p. 3].

The sender sends a non-verbal message by means of communication such as facial expressions, gestures, external appearance, as well as used objects and objects forming the background. These objects can carry information about beliefs, interests, shape the image of the speaker. So significant can be e.g. paintings on the walls (in what style, what the sender has, what he likes, how the apartment is furnished), items related to practiced religion (e.g. a cross on the wall, holy paintings), pieces of furniture (which style e.g. modern, rustic, etc.), sitting at a large desk, the top of which is visible (power distance), posters and attributes indicating, for example, belonging to a fan club; objects that build the image of the sender, e.g. as an intellectual (conversation against bookshelves and books, or books) or as a technical expert (conversation against electronic devices), children's attributes (communicating that the interlocutor is a parent), etc. Examples could be multiplied. The awareness that what is shown behind the back of a video chat participant is significant at a non-verbal level must be considered one of the basic elements of communication competence. Firstly, you need to pay attention to how the space is arranged. Secondly, consider what this means and whether these meanings coincide with the sender's intention. Thirdly, possibly rearrange the space as intended. An indirect confirmation of the background weight in audio-visual communication is the background blur option commonly available in messengers, which prevents an unauthorized interlocutor from accessing a non-verbal message carried by objects surrounding the interlocutor. In addition to the main reasoning, it should be mentioned that the ar- 
rangement of space and its use in non-verbal communication can also be manipulative when the sender wants to suggest to the recipient meanings that differ from the actual state [Riggio, 2005, 119-138].

\section{Proxemics in the practice of video communication - empirical research}

\section{Participating observation - description of the empirical study}

The multi-faceted nature of the phenomenon discussed makes it difficult to provide a closed set of categories related to the role of proxemics in audio-visual mediated communication. The above considerations should be supplemented with an empirical context. The participant observation method was chosen to achieve this goal. The study concerned a meeting by means of an audio-video communicator Microsoft Teams, in which 23 people participated (13 women, 10 men). The meeting was official . In the same team, these people meet regularly (under normal circumstances) in the meeting room of the institution in which they are employed.

The basic social science method was used - implicit, uncontrolled participant observation. The researcher played a dual role: meeting participant and observer. Due to the actual involvement as a participant and the secondary nature of the observer role, there was no intentional misleading of participants to hide research activities. The research was conducted according to the author's questionnaire. The observation lasted 3 hours. The ethical standards of the study were maintained. Due to the obvious fragmentation of the research, they were used to support certain theses and as a source of examples, and not to formulate general conclusions about the phenomenon in question. The main purpose of the study was to observe the proxemics behaviour of participants and comments related to the proxemics of the communication situation in which they found themselves.

Conclusions from the observation: 1. Participants in the meeting presented themselves, in most cases, in living quarters such as the living room (one person had a conversation in the kitchen). 2. In most cases, the background was neutral (several people against the wall) or the background included bookshelves, paintings on the walls, pieces of furniture, a wall with diplomas or commemorative photos. 3 . The first topic raised by the participants did not concern substantive matters, but the unique circumstances of the meeting. A conversation took several minutes, during which participants commented on each other's surroundings, which was visible to them on the screens (e.g. what an interesting lamp, how many books do you have). 4. Several people spontaneously began to show other participants inaccessible fragments of their space on the screens (e.g. view outside the window, subsequent book shelves) [Tracy, Matsumoto, 2008, 1165511660]. 5. During the meeting, two people commented on what was happening in their space and justified their inattention (e.g. I am looking out of the window now because the cat is passing through the garden) and showed what they are looking at the moment. 6 . There were spontaneous questions about sharing information about hidden attributes resulting from having a meeting at home (e.g. do we all have a cup of coffee next to the computer? Let us see.) 7. There were statements expressing express interest in this unexpected access to private spaces of colleagues (Today all of us can look into our homes). 8. After the initial "fascination" with this possibility and partial comment on what was visible as the background, about half of the meeting participants resigned from the video chat and remained in voice contact, which probably allowed to perform other activities simultaneously.

\section{Changes, tensions, proxemics dilemmas - practical conclusions}

Empirical research conducted using the participatory observation method provided knowledge about the significant role of space in mediatized audio-visual communication. Studies have shown changes, tensions and proxemics dilemmas in video chats, often overlooked by those involved. Only the participant-observer's approach gave a 
greater chance to analyse the behaviour and proxemics elements that have a significant role in the communication process. This knowledge, of a contributory nature, can be the basis for deriving several practical conclusions to be used by both the creators of communicators, communication moderators, as well as participants in video chats or video conferences:

- new forms of communication require from users not only technical competence, but also reflection on communication competence, including non-verbal communication;

- there is a risk that what is "on screen" will not be distinguished from what is real (this is one of the main issues of media education). It follows from the above that the same competence in the field of non-verbal communication in screen contact cannot be applied. This will negatively affect both the course of individual communication acts and future relations with given persons in general (e.g. unclear status of individual persons); - you need to be aware that when dealing with professional and official matters by means of a video chat, we provide the interlocutor with non-verbal information about yourself that is hidden in real social distance. Which may result in the situation that the verbal layer of our communication will be inadequate to the non-verbal layer (e.g. a member of the European Parliament expressing via Skype for an television news program on the economic and social consequences of the epidemic occurring in a pink sweatshirt, with a mug in hand, from a room filled with trinkets emphasizing the private nature of this place);

- changes in the scope of interpersonal distance in relation to individual persons occur basically one-way. So in our relationships we maintain a certain interpersonal distance or shorten it. Hasty shortening of interpersonal distance during mediatized communication will also be transferred to face-to-face contact. Increasing the distance, after it has been shortened once, is a very negative signal in Polish culture;

- video chat in traditional media (these rules should be even stricter - but that's a different topic).

$\star \star \star$

Summing up our analyses regarding the re-evaluation of the proxemics code in mediatized communication, it is worth paying attention to three important aspects.

Firstly, in proxemics, spatial relationships mean relations with man. The consequence of the functioning of the new media messengers is blurring the boundaries of reality of what is near and what is far away. In this way, a new semantics is introduced for the understanding of human being "here" and "now", in specific time-space conditions. Media proxemics reject the need for directness, replaced by "being there" in the conditions of "here" and "now." New media contexts in which relationships between people meet do not allow for a classical understanding of space as a natural, physical environment of a human being, much less for considering them in terms of traditional proxemics models. Our analyses have shown that there is a need to modify these models to the dynamic reality of mediatized interpersonal communication. Failure to consider this transformation of the role of space in communication using modern messengers can increasingly weaken the cognitive value of traditional communication models.

Secondly, proxemics basically assumes and implies the directness of communication contact, it also assumes the adoption of various conditions of spatial relations in interpersonal and social communication. The classical semantics of space in the approach proposed by Hall was reflected and justified in relation to traditional media, which were characterized by a fairly unambiguous and legible semantic model. This model has fundamentally changed with the advent of online audio-visual messengers, where - in the reality and context of new audio-visual spaces - a new semantics of space has appeared. Our analyses have shown that the concepts of tele-presence and tele-participation are 
also undergoing transformation. Tele-participation in the communication process first implies tele-presence. It means the experience of being in a different spatial place or environment than that in which man is physically present. Tele-presence would mean participating in the process of communication beyond the dimensions of physical space in a virtual space in which our senses are immersed and which remains with us in an interactive relationship occurring in real time [Drożdż, 2005, p. 69-76]. Our analyses have revealed a new quality of tele-participation in communication, where the communication process is not realized in traditional spatial dimensions which are the basic information carrier, but in the dimensions of mediatized space, while maintaining and communicating the own space of all participants of communication in virtual space. In this way, synergistic strengthening of the role of proxemics elements in communication occurs.

Thirdly, our analyses have shown that understanding of interpersonal communication distance, experience of spatial territoriality have changed in the era of electronic media so that these spatial qualities acquire the character of a new cultural artefact, a media artefact. New ICT and media technologies have changed not only the quality of interpersonal communication in spatial relations, but also changed the perspective of the dependence of behaviour of social communication participants on new media spatial relations. Traditional proxemics and chronemic schemes, determining the way of life and communication of man, have undergone fundamental changes. The quality of these changes is so dynamic that it requires solid research analysis. We hope that our analyses have unveiled some theoretical and empirically contributing changes, tensions and proxemics dilemmas, the knowledge of which can contribute to the improvement of modern communication tools that increasingly take into account the role of space in communication and will inspire and help in acquiring new proxemics communication competences.

\section{References:}

ALBERT M. (2019), Nonverbal Communication, [in:] Kühnhardt L., Mayer T. (eds.), The Bonn Handbook of Globality, Springer, Cham.

BAYM, N. (1995), The emergence of community in computer-mediated communication, [in:] Jones S. G. (ed.), CyberSociety: Computer-Mediated Communication and Community, Sage, Thousand Oaks CA.

BEAULIEU C.M.J. (2004), Intercultural study of personal space: A case study, Journal of Applied Social Psychology, 34 (4), 794-805.

BIELECKA-PRUS J. (2012), [in:] Problem kontekstu w teoriach komunikowania społecznego. Studia Socjologiczne, vol. 1 (204).

DROŻDŻ M. (2005), Logos i etos mediów. Dyskurs paradygmatyczny filozofii mediów, Biblos, Tarnów.

HALL E. (1966), Hidden dimension, Garden City, N.Y., Doubleday.

HALL E.T. (1959), The silent language, Garden City, N.Y., Doubleday.

HALL E.T. (1974) Handbook for Proxemic Research, Washington, DC, Society for the Anthropology of Visual Communication.

HALL E.T. (2003), Ukryty wymiar, Warszawa, MUZA S.A.

HANS A., HANS E. (2015), Kinesics, Haptics and Proxemics: Aspects of Non -Verbal Communication Journal of Humanities and Social Science (IOSR-JHSS), 20, 2, p. 47-52, DOI: 10.9790/0837-20244752.

HARELI S., HESS U. (2010), What emotional reactions can tell us about the nature of others: An appraisal perspective on person perception, Cognition and Emotion, 24, 128-140.

HENDRYKOWSKI M. (2016), Proksemika. Studia z semiotyki i antropologii kultury, Poznań, Wydawnictwo Naukowe UAM.

KNAPP M.L. (1979), Nonverbal Communication in Human Interaction, New York, Holt, Rinehart and Winston.

KNUT LUNDBY K., MOUTON DE G., (2014), Mediatization of Communication, Series: Handbooks of Communication Science [HoCS], 21, DOl: https://doi.org/10.1515/9783110272215.

LI S. (2001), How close is too close? A comparison of proxemic reactions of Singaporean Chinese to male 
intruders of four ethnicities, Perceptual and Motor Skills, 93 (1), 124-146.

LUSTIG M.W., KOESTER J. (1996), Intercultural competence: Interpersonal communication across cultures, New York: HarperCollins.

MICHALCZYK S. (2009), Pojęcie mediatyzacji w nauce o komunikowaniu, [in:] Kolczyński M., Mazur M., Michalczyk S. (ed.), Mediatyzacja kampanii politycznych, Wydawnictwo Uniwersytetu Śląskiego, Katowice.

NĘCKI, Z. (2000), Komunikacja międzyludzka, Kraków, Antykwa.

PIÓRO Z. (1982), Ekologia społeczna - nauka o strukturach i zachowaniach przestrzennych, [in:] Pióro Z. (ed.), Przestrzeń i społeczeństwo. Z badań ekologii społecznej, Książka i Wiedza,Warszawa.

Proksemika, [in:] Encyklopedia PWN [online: March 20], https://encyklopedia.pwn.pl/haslo/proksemika;3962569. html

RIGGIO R.E. (2005), Business Applications of Nonverbal Communication, [in:] R.E. Riggio \& R.S. Feldman (Eds.), Applications of nonverbal communication, Lawrence Erlbaum Associates Publishers, 119-138.

SPROULL, L., KIESLER, S. (1986), Reducing social context cues: Electronic mail in organizational Communication, [in:] Management science, vol. 32(11).

TRACY J.L., MATSUMOTO D. (2008), The spontaneous expression of pride and shame: Evidence for biologically innate nonverbal displays, Proceedings of the National Academy of Sciences 105 (33), 11655-11660. 